\title{
Weight Bias, Health Consciousness and Behavioral Actions (activities)
}

\author{
Matthew Wood \\ Brighton Business School, University of Brighton, Brighton, United Kingdom \\ Paurav Shukla \\ Essex Business School, University of Essex, Colchester, United Kingdom
}

Received 10 June 2016, Revised 16 September 2016, Accepted 18 October 2016, Available online 20 October 2016

Objective: This study examines the influence of weight bias and health consciousness on eating and
dietary behavior; it also investigates the role of normative influences. Design and Methods: A representative sample of adults living in South-East England $(N=498)$ completed anonymous questionnaires about their diet, attitudes and beliefs towards obese people, health consciousness and normative influences. The survey included validated measures of anti-fat attitudes, and beliefs about obese people.

Results: The findings demonstrate anti-fat attitudes are positively related to self-perceived dietary behavior. Surprisingly, self-perceived dietary behavior is negatively related to health consciousness and activities designed to enable healthy eating, for example meal planning. Significant differences exist between people with, or without, obese family members.

Conclusions: Attempts to improve eating behavior by raising health consciousness and offering related support activities may fail; promoting health eating may also contribute to weight bias in society. However, interventions which focus on the negative impact of obesity itself may have a positive effect.

\section{Introduction}

The continuing rise in obesity rates (Organization \& World Health, 2008; Stevens et al., 2012) has been accompanied by an increase in anti-fat attitudes, prejudice against, and stigmatization of, overweight individuals (Puhl et al., 2015; Puhl, Peterson, DePierre, \& Luedicke, 2013) and in response, the rise of the fat-acceptance movement (Afful \& Ricciardelli, 2015). Weight bias can be defined as the tendency to hold negative attitudes toward someone based upon their weight (Washington, 2011). Rising obesity rates have caused increasing health and economic challenges because of resulting conditions such as type II diabetes, liver and cardio-vascular diseases. Governments across the world are spending billions of dollars in awareness campaigns to raise health consciousness and encourage healthy eating behavior (World Health Organization, 2016). The EU has budgeted almost $€ 450$ million for health promotion over seven years (European Parliament, 2015). The UK government is spending $£ 75$ over three years on its Change4Life obesity program (NHS, 2016). The aim of many of these campaigns is to instigate proactive behaviors such as dietary consciousness and supportive planning activities, for example meal and diet plans. The underlying assumption is an individual makes choices in a rational, linear manner and planned behavior leads to particular actions. However, prior research has looked at these action mechanisms in isolation and therefore does not investigate the relationship between these behaviors. For example, the Baltimore Healthy Eating Zones intervention focused on increasing availability and selection of healthier foods through nutrition promotion and education using point-of purchase materials such as posters and flyers in stores (Varraso et al., 2015). On the other hand, the Healthy Home Offerings via the Mealtime Environment (HOME) Plus study on support activities focuses on meal-planning skills (Fulkerson et al., 2014). In extending earlier research, we simultaneously investigate the role of two negative individual tendencies: weight bias, and belief about obese people; and two positive tendencies: health consciousness and normative influences, on self-perceived dietary behavior and support activities for healthy eating. By understanding the attitudes and behavior of the wider population, this study offers insights to health professionals and policy makers in terms of how each of these negative and positive individual tendencies influences proactive healthy actions.

Weight bias causes discrimination against overweight people in many domains: education (Caird et al., 2011), employment (O'Brien, Latner, Ebneter, \& Hunter, 2013), and in healthcare (Puhl \& Brownell, 2006; Teachman \& Brownell, 2001). The consequences can be serious, for example overweight people are more likely to suffer from depression (Luppino et al., 2010), low self-esteem (Franklin, Denyer, Steinbeck, Caterson, \& Hill, 2006), and to be socially and economically disadvantaged (Sarlio-Lähteenkorva \& Lahelma, 1999). Individuals who exhibit this type of discriminatory behavior tend to hold a set of stereotypical, negative beliefs about obese people (Puhl, Moss-Racusin, Schwartz, \& Brownell, 2008). Research has shown a similar distribution of such negative beliefs amongst health professionals as the general population (Wise, Harris, \& Olver, 2014), and even among overweight respondents (Schwartz, Vartanian, Nosek, \& Brownell 2006). Apart from establishing there is a consistent level of weight bias amongst countries as diverse as Iceland, USA and Australia - and higher levels amongst men in all countries, Puhl et al., (2015) also found individuals with family members or friends who had experienced bias were less likely to hold these attitudes themselves. 
While the discriminatory effects of weight bias are highlighted in extant studies, there is little research on how weight bias affects healthy actions and relates to health consciousness. According to prior research, health consciousness is a good predictor of healthy eating behavior (Hearty, McCarthy, Kearney, \& Gibney, 2007). A field experiment found it was a useful marker of mothers' behavior related to ensuring their child's compliance with a prescribed diet and follow-up clinical appointments (Becker, Maiman, Kirscht, Haefner, \& Drachman, 1977). Another study explored the relationship between health values, locus of control and healthy lifestyles (Steptoe \& Wardle, 2001). For several diet-related behaviors health conscious individuals exhibit high levels of self-control and reported healthy lifestyles. However, some researchers have questioned the validity of the assumption that health beliefs and consciousness result in healthier behaviors (Michaelidou \& Hassan, 2008; Newsom, McFarland, Kaplan, Huguet, \& Zani, 2005). The first of these studies involved the analysis of data from 250,000 American respondents; it found no association between behaviors such as smoking, drinking, exercise and diet, and concluded health consciousness was a myth. The second study took place in the U.K. and concluded health consciousness is a weak predictor and motivator for the consumption of organic foods. Research has found a mismatch between quantitative measures of health consciousness, and nutritional knowledge and qualitative insights into eating behavior (Pohlmeier, Reed, Boylan, \& Harp, 2012). Furthermore, orthorexia has been recognized as an eating disorder which negatively affects individuals who are overly health conscious, and become obsessed with healthy eating (Dunn and Bratman, 2016). Thus, the findings relating to the role played by health consciousness on shaping behavioral actions are inconclusive. This study aims to investigate this role and also explores how normative influences affect health eating behavior and related support activities. Burnkrant and Cousineau (1975) define normative influences as the tendency to conform to the expectations of others. Normative influences can influence health behaviors, including diet (Higgs, 2015). They can also influence weight bias (Puhl et al, 2015). While it is demonstrated that normative influences do play a significant role in food choice and dietary behavior (Salvy, de la Haye, Bowker, \& Hermans, 2012), this research looks at the particular impact on eating behavior and healthy eating support activities. Following an earlier study (Puhl et al., 2015) this research examines how overweight family members influence eating behavior and weight bias. It addresses questions such as: are individuals who exhibit high levels of weight bias more or less likely to eat healthily? How is health consciousness related to eating behaviors? How do normative influences impact diet? The current study explores the relationship between anti-fat attitudes, beliefs about obese people, health consciousness, normative influences - including the effect of having an overweight family member -and short and medium-term behavioral responses; namely healthy eating behavior and support activities, such as using menu plans and food diaries.

\section{Method}

\subsection{Participants and procedure}

The study was conducted amongst a sample of residents from South-East England. Respondents completed an on-line questionnaire anonymously using Qualtrics proprietary software. The study and questionnaire were approved by the university research ethics and governance committee. The study was explained to participants and informed consent was obtained before asking a series of attitudinal and behavioral questions (see below) relating to their attitudes towards obesity, and their own health consciousness, eating behaviors and normative influences. Data was collected over a five-week period during spring and summer of 2013.

More than 1500 potential respondents were contacted using a mix of university networks, social media channels, regional health groups and local issues forums. In total, 524 responses were received. However, 26 questionnaires were incomplete and therefore rejected, leaving a final usable sample of 498 (response rate $=33.20 \%$ ). Of the total sample $61.80 \%$ of the participants were female, and the average age $32(S D=12.27)$. The largest marital status category was single $(56.00 \%)$ followed by married $(22.10 \%)$ and living with a partner $(16.30 \%)$, with $42.17 \%$ of all respondent having an undergraduate degree or equivalent. Average participant BMI was $22(S D=3.24)$. On the weight dimension, $9.00 \%$ of the respondents were underweight (BMI < 18.5), 75.30\% with normal weight (BMI 18.5 to 24.9), 13.50\% overweight (BMI 25.0 to 29.9) and $2.20 \%$ obese $(\mathrm{BMI} \geq 30)$.

The analysis was carried out using LISREL 8.8 with maximum likelihood estimation procedure. We first developed a measurement model to test the validity and reliability followed by a structural model to test the relationship between constructs. We further tested these relationships by dividing our data in two specific groups: those with overweight or obese people in immediate family $(N=256)$ and those with none $(N=242)$.

\subsection{Measures}

The questionnaire was divided in three parts with question groups randomized. Part one recorded socio-demographic information. Part two captured the independent (i.e. anti-fat attitudes, health consciousness, belief about obese people and normative influences) and dependent variables (i.e. healthy eating behavior and maintaining healthy actions). Items relating to each independent and dependent variable were derived from existing scales (see Table 2 for a full list of items). The last part recorded participants' own estimates of their height and weight. The scale items were counterbalanced by changing their order in the questionnaire.

2.2.1 Demographic and weight information. Participants completed demographic questions including age, gender, income, marital status and education. Height and weight data were collected to determine the BMI of participants. BMI was calculated and classified based on the clinical guidelines for overweight and obesity in adults issued by the National Institute 
for Health and Care Excellence (NICE), UK. Participants were also asked if they had a family member whom they would consider overweight or obese using a "yes" or "no" response. Table 1 below gives full sample details.

2.2.2 Anti-fat attitudes. Participants' anti-fat attitudes were measured using five items from Crandall's anti-fat attitudes questionnaire (AFAT) (Crandall, 1994). Items were presented with 9-point Likert-type rating scale with "very strongly disagree" and "very strongly agree" as anchors (Cronbach's alpha $=0.83$ ).

2.2.3 Beliefs about obese people. Participants were asked to reflect on their agreement/disagreement regarding beliefs about obese people (Allison, Basile, \& Yuker, 1991). The responses were captured through a staple scale with -3 (I strongly disagree) to +3 (I strongly agree) as anchors. The scale reliability (Cronbach's alpha $=0.70$ ) was above the threshold.

2.2.4 Health consciousness. Respondents were asked seven questions about their health consciousness based the scale developed by Gould ( 1988). These items were measured on a 5-point Likert-type scale $(1=$ Does not describe you at all; $5=$ Describes you very well). The Cronbach's alpha was 0.89 .

2.2.5 Normative influences. Normative influences were measured through items developed by Flynn et al ( 1996). These items were measured on a 7-point Likert scale $(1=$ Strongly disagree; $7=$ Strongly agree $)($ Cronbach's alpha $=0.84)$.

2.2.6 Self-perceived dietary behavior. Participants were then asked 4 questions about their eating behavior based on the scale developed by Hearty et al. ( 2007). Measurements were taken using a 5-point scale with "most of the time" and "hardly ever" as anchors (Cronbach's alpha $=0.70)$.

2.2.7 Support activities for healthy eating. To assess participants' ability to maintain healthy actions three questions were asked based on Sallis et al.'s scale (Fornell \& Larcker, 1981; Sallis, Pinski, Grossman, Patterson, \& Nader, 1988). The construct was measured through 5-point scale ( 1 = Sure I could not do it; $5=$ Sure I could do it) (Cronbach's alpha $=0.72)$.

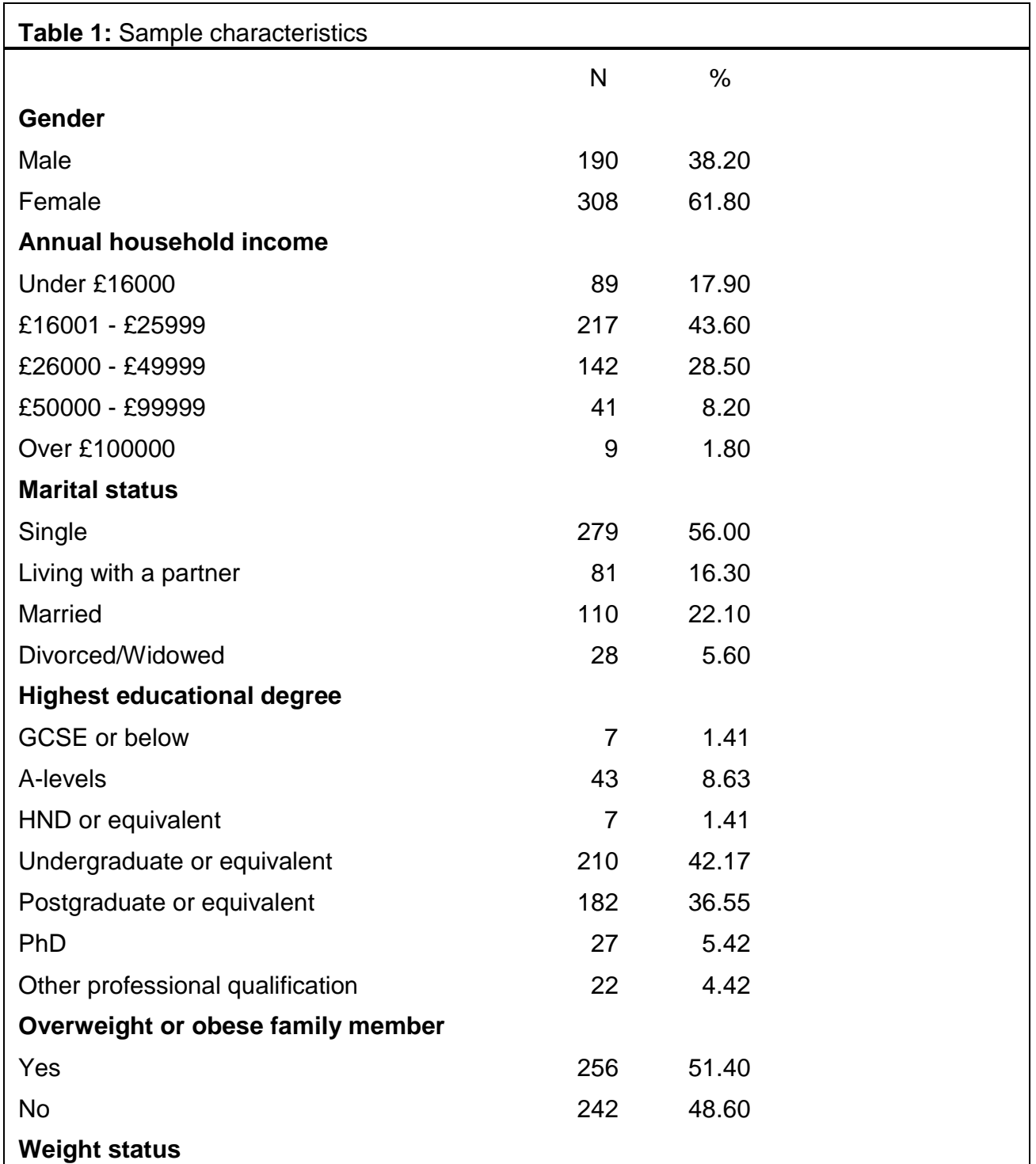




\begin{tabular}{|lrrrr|} 
Underweight & 45 & 9.00 & & \\
Normal weight & 375 & 75.30 & & \\
Overweight & 67 & 13.50 & & \\
Obese & 11 & 2.20 & & \\
\hline & $\mathrm{N}$ & $\mathrm{M}$ & SD & $\alpha$ \\
\hline BMI & 498 & 21.99 & 3.24 & \\
\hline Age (years) & 498 & 32.08 & 12.27 & \\
\hline
\end{tabular}

\section{Results}

\subsection{Regression analyses}

The measurement model (Table 2) indicators show an excellent fit $\left[\chi^{2}(\mathrm{df})=584.45\right.$ (279); Root Mean Square Error of Approximation $($ RMSEA $)=0.048$; Non-Normed Fit Index $(\mathrm{NNFI})=0.95$; Comparative Fit Index $(\mathrm{CFI})=0.95$; Goodness of Fit Index $(\mathrm{GFI})=0.92]$. Additionally, the Cronbach's alpha above 0.7 , composite reliability $(\mathrm{CR})$ above 0.7 and the Average Variance Extracted (AVE) above 0.5 were observed for all the variables and constructs demonstrating a reliable model.

\begin{tabular}{|c|c|c|c|c|}
\hline Table 2: Standardized estimates, AVE, CR and Alpha values. & $\begin{array}{l}\text { Standardized } \\
\text { Estimates }\end{array}$ & $\begin{array}{l}\text { AV } \\
\mathrm{E}\end{array}$ & CR & Alpha \\
\hline Health consciousness $(M=3.32 ; S D=0.91)$ & & 0.80 & 0.89 & 0.90 \\
\hline I reflect about my health a lot & 0.75 & & & \\
\hline I am very self-conscious about my health & 0.76 & & & \\
\hline I am generally attentive to my inner feelings about my health & 0.67 & & & \\
\hline I am consistently examining my health & 0.75 & & & \\
\hline I am alert to changes in my health & 0.73 & & & \\
\hline I notice how I feel physically as I go through the day & 0.64 & & & \\
\hline I am very involved with my health & 0.77 & & & \\
\hline Belief about obese persons $(M=4.73 ; S D=0.83)$ & & 0.55 & 0.74 & 0.74 \\
\hline Obesity is rarely caused by a lack of willpower & 0.69 & & & \\
\hline Most obese people cause their problem by not getting enough exercise & 0.66 & & & \\
\hline Most obese people eat more than non-obese people & 0.65 & & & \\
\hline The majority of obese people have poor eating habits that lead to their obesity & 0.58 & & & \\
\hline Antifat attitudes $(M=3.22 ; S D=1.48)$ & & 0.74 & 0.84 & 0.86 \\
\hline I really don't like fat people much & 0.57 & & & \\
\hline I tend to think that people who are overweight are a little untrustworthy & 0.74 & & & \\
\hline $\begin{array}{l}\text { Although some fat people are surely smart, in general, I think they tend not to be } \\
\text { quite as bright as normal weight people }\end{array}$ & 0.73 & & & \\
\hline I have a hard time taking fat people too seriously & 0.89 & & & \\
\hline If I were an employer looking to hire, I might avoid hiring a fat person & 0.64 & & & \\
\hline
\end{tabular}




\begin{tabular}{|c|c|c|c|c|}
\hline Normative influences $(M=3.70 ; S D=1.48)$ & & 0.77 & 0.84 & 0.88 \\
\hline When I consider buying healthy food/drinks, I ask other people for advice. & 0.76 & & & \\
\hline I like to get others opinions before I buy healthy food/drink products. & 0.80 & & & \\
\hline $\begin{array}{l}\text { I feel more comfortable buying a healthy food/drink product when I have gathered } \\
\text { other people's opinions on it. }\end{array}$ & 0.84 & & & \\
\hline Self-perceived dietary behavior $(M=2.22 ; S D=0.63)$ & & 0.54 & 0.74 & 0.74 \\
\hline I make conscious effort to try and eat a healthy diet & 0.68 & & & \\
\hline I try to keep the amount of fat I eat to a healthy amount & 0.72 & & & \\
\hline I try to ensure I eat plenty of fruits and vegetables & 0.58 & & & \\
\hline I usually avoid eating fried foods & 0.59 & & & \\
\hline Support activities for healthy eating $(M=2.95 ; S D=1.04)$ & & 0.57 & 0.73 & 0.75 \\
\hline Post a weekly menu plan on your kitchen bulletin board & 0.69 & & & \\
\hline Keep a food diary for one week if you begin to slip in your food program & 0.78 & & & \\
\hline Keep problematic high-salt, high-fat foods out of sight, if purchased & 0.59 & & & \\
\hline
\end{tabular}

To assess the discriminant validity (that is to show that measures that should not be related are in reality not related), the average variance extracted was compared with the variance shared between all construct pairs (Fornell \& Larcker, 1981). This test suggests that a scale possesses discriminant validity if the average variance extracted by the underlying latent variable is greater than the shared variance (i.e., the squared correlation) of a latent variable with other latent variables. This criterion was met by all constructs (Table 3 ). The composite reliability is found to be above 0.7 across the constructs, exceeding the recommended threshold value, which also provides strong evidence of discriminant validity.

\begin{tabular}{|c|c|c|c|c|c|c|}
\hline Table 3: Correlations matrix & $\mathrm{HC}$ & BOP & AFA & NI & SDB & SAH \\
\hline Heath consciousness (HC) & 0.90 & & & & & \\
\hline Belief about obese people (BOP) & 0.14 & 0.74 & & & & \\
\hline Anti-fat attitudes (AFA) & 0.07 & -0.04 & 0.86 & & & \\
\hline Normative influences (NI) & 0.07 & -0.03 & 0.33 & 0.88 & & \\
\hline Self-perceived dietary behavior (SDB) & -0.38 & -0.02 & 0.18 & 0.18 & 0.74 & \\
\hline Support activities for healthy eating (SAH) & 0.25 & 0.11 & 0.09 & -0.04 & -0.25 & 0.75 \\
\hline
\end{tabular}

Note: The figures in italics show the squared Average Variance Extracted values (AVE).

Table 4 shows the path coefficients based on the structural equation model for the predictor and criterion variables. The direct effect of health consciousness was significant on both healthy eating behavior and maintaining healthy actions. However, the relationship was negative for self-perceived dietary behavior while positive for support activities for healthy eating, Anti-fat attitudes had a positive relationship to self-perceived dietary behavior but did not have a significant association with support activities for healthy eating. Normative influences had a significant positive influence on selfperceived dietary behavior and negative influence on support activities for healthy eating.

\begin{tabular}{|l|c|c|}
\hline Table 4: Path coefficients & Self-perceived dietary behavior & Support activities for healthy eating \\
\hline Health consciousness & $-0.31^{* * *}$ & $0.19^{* * *}$ \\
\hline
\end{tabular}




\begin{tabular}{|l|c|c|}
\hline Belief about obese persons & -0.11 & 0.06 \\
\hline Anti-fat attitudes & $0.16^{* * *}$ & 0.09 \\
\hline Normative influences & $0.25^{* * *}$ & $-0.23^{* * *}$ \\
\hline Support activities for healthy eating & $-0.16^{* * *}$ & NA \\
\hline
\end{tabular}

Significance levels: $* * *<0.001 ; * *<0.01 ; *<0.05$.

\subsubsection{Influence of presence of obese family member}

As can be seen in Table 5, only health consciousness was significantly associated with support activities for healthy eating among families with overweight or obese people. There was a significant, negative relationship between health consciousness and self-perceived dietary behavior. There was also a significant, positive relationship between self-perceived dietary behavior and normative influences among people who had an overweight or obese person in family. There was a significant, negative association between beliefs about obese people and self-perceived dietary behavior amongst this group. Health conscious participants without overweight or obese people in their family also tend to use support activities for healthy eating. However, there is a negative relationship between support activities and normative influences. Self-perceived dietary behavior in this group is significantly influenced by health consciousness (negatively), anti-fat attitudes and normative influences.

\begin{tabular}{|l|c|c|c|c|}
\hline $\begin{array}{l}\text { Table 5: Presence of obese } \\
\text { family member }\end{array}$ & \multicolumn{2}{|c|}{ Families with obese people } & \multicolumn{2}{c|}{ Families without obese people } \\
\hline & $\begin{array}{c}\text { Self-perceived } \\
\text { dietary behavior }\end{array}$ & $\begin{array}{c}\text { Support activities for } \\
\text { healthy eating }\end{array}$ & $\begin{array}{c}\text { Self-perceived } \\
\text { dietary behavior }\end{array}$ & $\begin{array}{c}\text { Support activities for } \\
\text { healthy eating }\end{array}$ \\
\hline Health consciousness & $-0.18^{* * *}$ & $0.17^{* *}$ & $-0.22^{* * *}$ & $0.19^{* *}$ \\
\hline Belief about obese persons & $-0.10^{* *}$ & 0.08 & -0.04 & 0.13 \\
\hline Anti-fat attitudes & 0.05 & 0.003 & $0.08^{* * *}$ & 0.07 \\
\hline Normative influences & $0.07^{* *}$ & -0.07 & $-0.07^{* *}$ & NA \\
\hline $\begin{array}{l}\text { Support activities for } \\
\text { healthy eating }\end{array}$ & $-0.14^{* * *}$ & NA & & $-0.12^{* *}$ \\
\hline
\end{tabular}

Significance levels: $* * *<0.001 ; * *<0.01 ; *<0.05$.

\section{Discussion}

This study investigates the positive and negative effects of health consciousness, beliefs about obese people, weight bias, normative influences on behavioral responses - self-perceived dietary behavior and support activities for healthy eating and shows how these relationships can contribute to the development of effective health interventions. The most interesting and surprising - finding was the significant, positive relationship between anti-fat attitudes and self-perceived dietary behavior. Respondents scoring highly on the anti-fat attitudes scale were more likely to attempt to achieve a healthy diet. A possible explanation is the tendency amongst some normal weight people to make moral judgements about obese individuals, who are deemed responsible for their own situation (Hofmann, 2016; Pieterman, 2015). This association has important implications for behavioral change and public health initiatives targeting overweight individuals. This study suggests interventions which incorporate anti-fat attitudes may influence some groups to eat more healthily. Health promotion professionals tend to caution against the use of negative messages and shock tactics in behavior change programs (Hastings, Stead, \& Webb, 2004). However, with careful research and development the association between anti-fat attitudes and healthy eating could be used to develop more effective interventions and campaigns. This is an area which requires more research but these findings may offer the opportunity to reduce health inequalities through converting a negative, harmful trait (anti-fat attitudes) into a positive behavior (healthy eating and lifestyle).

Extant research is inconclusive on the impact of health consciousness on healthy actions; our findings offer valuable insights by separating dietary behavior from support activities designed to enable healthy eating. The findings show a positive link between health consciousness and support activities, for example menu plans and food diaries, but not between health consciousness and self-perceived dietary behavior; in other words, these constructs act separately. The strongly negative 
association between health consciousness and self-perceived dietary behavior is a highly significant finding. It appears that health consciousness may be raised when an individual is made aware of health-related weight issues. He or she may be conscious of their own health in relation to food but unable to translate this into behavioral change. This fundamentally transforms the way we should think about health promotion and behavioral change campaigns. A health conscious individual is not necessarily leading a healthy lifestyle and, in reality, the opposite may be true. Attempts to build on or develop awareness of health may be ineffective - or potentially counter-productive - when addressing weight "issues". We further examined the influence of support activities designed to enable healthy eating and self-perceived dietary behavior, finding a significantly negative relationship. This suggests there is a tenuous link between health consciousness, support activities for healthy eating and self-perceived dietary behavior. Weight-loss interventions typically aim to raise health consciousness and often include the use of food diaries and menu planners, which health professionals believe to be supportive, practical ways of enabling behavior change. Our findings imply these actions may motivate the individual to maintain a plan and diary but this may not develop into healthy eating behavioral patterns (Townsend \& Liu, 2012). Earlier research has shown the value of planning and self-monitoring techniques in achieving healthy eating (Michie et al., 2009). We believe that the greater focus on planning may increase the effort required to self-regulate, resulting in ego or self-control depletion, which acts as a barrier to resisting unhealthy foods and achieving healthy dietary behavior (Geisler, Kleinfeldt, \& Kubiak, 2016; Inzlicht, Berkman, \& Elkins-Brown, 2014).

There is a positive relationship between normative influences - the tendency to conform to the expectations of others - and self-perceived dietary behavior but a negative association with support activities for healthy eating. This has implications for food choice/weight loss interventions which rely on advice seeking/giving behavior and the use of professional and peer advisors/role models. Certain groups are happy to seek advice from others concerning what they should eat, but not how they should devise menus and plans. This reinforces the doubt expressed earlier about the efficacy of building advice and menuplanning etc. into behavior change interventions. Normative influences are often most powerful within the home environment. We found significant differences between people who have overweight/obese family members and those who do not. Individuals with anti-fat attitudes from families without obese close relatives practice healthy eating behavior. However, within this group there is a negative association between normative influences and support activities for healthy eating. There is a significant, negative relationship between belief about obese people and healthy eating behavior in families with obese members. Consequently, presence or otherwise of an obese family member should be used as a control factor to differentiate between target groups when designing interventions and campaigns. Normative influences operative differently depending on whether an individual has a close relative they perceive to be overweight. Future research should fully explore the variable nature of normative influences on eating behavior to help in the design and delivery of more effective, targeted obesity interventions whilst addressing the issue of weight bias.

This is a correlational study with several limitations. Although large, the sample may not be representative of the entire population. Social desirability can influence responses when measuring explicit weight bias so future research should also use measures of implicit bias. Similarly, some respondents may have exaggerated their healthy-eating behavior. Future studies could include experimental designs and more objective behavioral measures such as observation and till receipts. The role of health consciousness and normative influences warrants further study, particularly in the context of family dynamics and role modelling. Deciding how, and when, to use planning/self-monitoring activities to help with food choices and diet would benefit from further research.

In conclusion, this study has contributed to our understanding of weight bias, its relationship with health consciousness and behavioral actions, and the implications of this for behavioral change policy and interventions. The findings confirm previous reports of the prevalence of weight bias amongst various groups. However, the finding that weight bias is positively associated with healthy eating behavior has important implications for how obesity programs should be designed and delivered. The findings also challenge the notion health consciousness leads to healthy eating behavior and that dietary planning tools will support positive behavior change around food. Normative influences are very important but operate differently depending on whether or not there is an obese relative in the family. Obesity has been labelled a "problem" behavioral or lifestyle issue by politicians, health professionals and social marketers. The intention of social marketers and public health professionals is to improve the health and life outcomes of target audiences by encouraging or enabling them to change behavior in order to lose weight. Some behavior change specialists argue approaches centered on changing the behavior of overweight individuals should be replaced by population-wide interventions and policy initiatives to tackle obesity (Schwartz \& Brownell, 2007). Our findings suggest the promotion of healthy eating through social marketing and educational programs should be accompanied by actions to dispel myths and assumptions about the causes of obesity.

\section{References}

Afful, A. a., \& Ricciardelli, R. (2015). Shaping the online fat acceptance movement: talking about body image and beauty standards. Journal of Gender Studies, 24(4), 453-472. http://doi.org/10.1080/09589236.2015.1028523

Allison, D. B., Basile, V. C., \& Yuker, H. E. (1991). The measurement of attitudes toward and beliefs about obese persons. International Journal of Eating Disorders, 10(5), 599-607. http://doi.org/10.1002/1098-108X(199109)10:5<599::AID-EAT2260100512>3.0.CO;2-\#

Becker, M. H., Maiman, L. A., Kirscht, J. P., Haefner, D. P., \& Drachman, R. H. (1977). The Health 
Belief Model and Prediction of Dietary Compliance: A Field Experiment. Journal of Health and Social Behavior, 18(4), 348-366.

http://doi.org/10.2307/2955344

Caird, J., Josephine, K., Oliver, K., Oliver, S., O'Mara, A., Stansfield, C., \& Thomas, J. (2011). Childhood obesity and educational attainment: a systematic review. London: EPPI-Centre, Social Science Research Unit, Institute of Education.

Crandall, C. S. (1994). Prejudice against fat people: ideology and self-interest. Journal of Personality and Social Psychology, 66(5), 882-894. http://doi.org/10.1037/0022-3514.66.5.882

Dunn, T. M., \& Bratman, S. (2016). On orthorexia nervosa: A review of the literature and proposed diagnostic criteria. Eating Behaviors, 21, 11-17. http://dx.doi.org/10.1016/j.eatbeh.2015.12.006

European Parliament, 2015. Briefing: How the EU Budget is Spent. Available at: http://www.europarl.europa.eu/RegData/etudes/BRIE/2015/573875/EPRS_BRI(2015)573875 _EN.pdf. (Accessed, 12/09/2016).

Flynn, L. R., Goldsmith, R. E., \& Eastman, J. K. (1996). Opinion Leaders and Opinion Seekers: Two New Measurement Scales. Journal of the Academy of Marketing Science, 24(2), 137-147. http://doi.org/10.1177/0092070396242004

Fornell, C., \& Larcker, D. F. (1981). Evaluation Structural Equation Models with Unobservable Variables and Measurement Error. Journal of Marketing Research, 18(1), 39 - 50. http://doi.org/10.2307/3151312

Franklin, J., Denyer, G., Steinbeck, K. S., Caterson, I. D., \& Hill, A. J. (2006). Obesity and risk of low self-esteem: a statewide survey of Australian children. Pediatrics, 118(6), 2481-2487. http://doi.org/10.1542/peds.2006-0511

Fulkerson, J. A., Neumark-Sztainer, D., Story, M., Gurvich, O., Kubik, M. Y., Garwick, A., \& Dudovitz, B. (2014). The Healthy Home Offerings via the Mealtime Environment (HOME) Plus study: Design and methods. Contemporary Clinical Trials, 38(1), 59-68. http://doi.org/10.1016/j.cct.2014.01.006

Geisler, F. C. M., Kleinfeldt, A., \& Kubiak, T. (2016). Restrained eating predicts effortful selfcontrol as indicated by heart rate variability during food exposure. Appetite, 96, 502-508. http://doi.org/10.1016/j.appet.2015.10.020

Hastings, G., Stead, M., \& Webb, J. (2004). Fear appeals in social marketing: Strategic and ethical reasons for concern. Psychology and Marketing. http://doi.org/10.1002/mar.20043

Hearty, Á. P., McCarthy, S. N., Kearney, J. M., \& Gibney, M. J. (2007). Relationship between attitudes towards healthy eating and dietary behavior, lifestyle and demographic factors in a representative sample of Irish adults. Appetite, 48(1), 1-11. http://doi.org/10.1016/j.appet.2006.03.329

Higgs, S., 2015. Social norms and their influence on eating behaviours.Appetite, 86, pp.38-44.

Hofmann, B., 2016. Obesity as a socially defined disease: Philosophical considerations and implications for policy and care. Health Care Analysis,24(1), pp.86-100.Inzlicht, M., Berkman, E., \& Elkins-Brown, N. (2014). The neuroscience of "ego depletion" or: How the brain can help us understand why self- control seems limited. Neuroscience of Depletion, 1-44. http://doi.org/10.1093/acprof:oso/9780199605606.001.0001

Lynagh, M., Cliff, K. and Morgan, P.J., 2015. Attitudes and Beliefs of Nonspecialist and Specialist Trainee Health and Physical Education Teachers Toward Obese Children: Evidence for "AntiFat" Bias. Journal of School Health, 85(9), pp.595-603.Luppino, F. S., de Wit, L. M., Bouvy, P. F., Stijnen, T., Cuijpers, P., Penninx, B. W., \& Zitman, F. G. (2010). Overweight, obesity, and depression: a systematic review and meta-analysis of longitudinal studies. Archives of General Psychiatry, 67(1538-3636 (Electronic)), 220-229. http://doi.org/10.1001/archgenpsychiatry.2010.2

Michaelidou, N., \& Hassan, L. M. (2008). The role of health consciousness, food safety concern and ethical identity on attitudes and intentions towards organic food. International Journal of Consumer Studies, 32(2), 163-170. http://doi.org/10.1111/j.1470-6431.2007.00619.x

Michie, S., Abraham, C., Whittington, C., McAteer, J. and Gupta, S., 2009. Effective techniques in 
healthy eating and physical activity interventions: a meta-regression. Health Psychology, 28(6), p.690-701.

Newsom, J. T., McFarland, B. H., Kaplan, M. S., Huguet, N., \& Zani, B. (2005). The health consciousness myth: Implications of the near independence of major health behaviors in the North American population. Social Science and Medicine, 60(2), 433-437. http://doi.org/10.1016/j.socscimed.2004.05.015

NHS. (2016). Change4Life, available at:http://www.nhs.uk/change4life/Pages/partner-frequentlyasked-questions.aspx\#question14 (accessed, 12/09/2016).

O'Brien, K. S., Latner, J. D., Ebneter, D., \& Hunter, J. A. (2013). Obesity discrimination: the role of physical appearance, personal ideology, and anti-fat prejudice. International Journal of Obesity, 37(3), 455-460. http://doi.org/10.1038/ijo.2012.52

Organization, W. H., \& World Health, O. (2008). World health statistics 2008. World Health Organisation, 36-54. Retrieved from http://www.who.int/whosis/whostat/EN_WHS08_TOCintro.pdf

Phelan, S. M., Dovidio, J. F., Puhl, R. M., Burgess, D. J., Nelson, D. B., Yeazel, M. W., ... Van Ryn, M. (2014). Implicit and explicit weight bias in a national sample of 4,732 medical students: The medical student CHANGES study. Obesity. http://doi.org/10.1002/oby.20687

Pieterman, R., 2015. Obesity as Disease and Deviance: Risk and Morality in Early 21st Century. In Contributions from European Symbolic Interactionists: Reflections on Methods (pp. 117138). Emerald Group Publishing Limited.

Pohlmeier, A., Reed, D. B., Boylan, M., \& Harp, S. (2012). Using Focus Groups to Develop a Nutrition Labeling Program within University Food Service. Family and Consumer Sciences Research Journal, 40(4), 431-443. http://doi.org/10.1111/j.1552-3934.2012.02121.x

Puhl, R. M., \& Brownell, K. D. (2006). Confronting and coping with weight stigma: an investigation of overweight and obese adults. Obesity (Silver Spring, Md.), 14(10), 1802-1815. http://doi.org/10.1038/oby.2006.208

Puhl, R. M., Latner, J. D., O’Brien, K., Luedicke, J., Danielsdottir, S., \& Forhan, M. (2015). A multinational examination of weight bias: Predictors of anti-fat attitudes across four countries. International Journal of Obesity, 39(7), 1166-1173. http://doi.org/10.1038/ijo.2015.32

Puhl, R. M., Moss-Racusin, C. A., Schwartz, M. B., \& Brownell, K. D. (2008). Weight stigmatization and bias reduction: Perspectives of overweight and obese adults. Health Education Research, 23(2), 347-358. http://doi.org/10.1093/her/cym052

Puhl, R. M., Peterson, J. L., DePierre, J. a, \& Luedicke, J. (2013). Headless, hungry, and unhealthy: a video content analysis of obese persons portrayed in online news. Journal of Health Communication, 18(6), 686-702. http://doi.org/10.1080/10810730.2012.743631

Sallis, J. F., Pinski, R. B., Grossman, R. M., Patterson, T. L., \& Nader, P. R. (1988). The development of self-efficacy scales for healthrelated diet and exercise behaviors. Health Education Research, 3(3), 283-292. http://doi.org/10.1093/her/3.3.283

Salvy, S. J., de la Haye, K., Bowker, J. C., \& Hermans, R. C. J. (2012). Influence of peers and friends on children's and adolescents' eating and activity behaviors. Physiology and Behavior. http://doi.org/10.1016/j.physbeh.2012.03.022

Sarlio-Lähteenkorva, S., \& Lahelma, E. (1999). The association of body mass index with social and economic disadvantage in women and men. International Journal of Epidemiology, 28(3), 445-449. http://doi.org/10.1093/ije/28.3.445

Schwartz, M. B., \& Brownell, K. D. (2007). Actions necessary to prevent childhood obesity: Creating the climate for change. In Journal of Law, Medicine and Ethics (Vol. 35, pp. 78-89). http://doi.org/10.1111/j.1748-720X.2007.00114.x

Schwartz, M. B., Vartanian, L. R., Nosek, B. a, \& Brownell, K. D. (2006). The influence of one's 
own body weight on implicit and explicit anti-fat bias. Obesity (Silver Spring, Md.), 14(3), 440-447.

http://doi.org/10.1038/oby.2006.58

Steptoe, A., \& Wardle, J. (2001). Locus of control and health behavior revisited: a multivariate analysis of young adults from 18 countries. British Journal of Psychology , 92(Pt 4), 659672.

http://doi.org/10.1348/000712601162400

Stevens, G. A., Singh, G. M., Lu, Y., Danaei, G., Lin, J. K., Finucane, M. M., ... Global Burden of Metabolic Risk Factors of Chronic Diseases Collaborating Group (Body Mass Index). (2012). National, regional, and global trends in adult overweight and obesity prevalences. Population Health Metrics, 10, 22.

http://doi.org/10.1186/1478-7954-10-22

Teachman, B., \& Brownell, K. (2001). Implicit anti-fat bias among health professionals: Is anyone immune? International Journal of Obesity, 25, 1525-1531. http://doi.org/10.1038/sj.ijo.0801745

Townsend, C., \& Liu, W. (2012). Is Planning Good for You? The Differential Impact of Planning on Self-Regulation. Journal of Consumer Research, 39(4), 000-000. http://doi.org/10.1086/665053

Varraso, R., Chiuve, S. E., Fung, T. T., Barr, R. G., Hu, F. B., Willett, W. C., \& Camargo, C. A. (2015). Alternate Healthy Eating Index 2010 and risk of chronic obstructive pulmonary disease among US women and men: prospective study. BMJ (Clinical Research Ed.), 350, h286.

http://doi.org/10.1136/bmj.h286

Washington, R. L. (2011). Childhood obesity: issues of weight bias. Preventing Chronic Disease, $8(5)$, A94-A94. http://doi.org/A94 [pii]

World Health Organization. (2016). Global Health Expenditure Database. Available at: http://www.who.int/health-accounts/ghed/en/ (Accessed on: 12 Sep 2016).

Wise, F. M., Harris, D. W., \& Olver, J. H. (2014). Attitudes to obesity among rehabilitation health professionals in Australia. Journal of Allied Health, 43(3), 162-168. 